\title{
Removal of pyrazinamide and its by-products from water: Treatment by electro-Fenton process and feasibility of a biological post-treatment
}

\author{
Mohamed R. Arhoutane 1,", Muna Sh. Yahya ${ }^{1}$, Miloud El Karbane ${ }^{2}$, Aicha Guessous ${ }^{1}$, Hind Chakchak ${ }^{3}$ \\ and Kacem El Kacemi ${ }^{1}$ \\ ${ }^{1}$ Laboratoire d'Électrochimie et Chimie Analytique (LECA), département de chimie, Faculté des Sciences de \\ Rabat, Université Mohammed V, Rabat, Maroc \\ ${ }^{2}$ Laboratoire de Chimie Analytique et Bromatologie, Faculté de Médecine et de Pharmacie, Université \\ Mohamed V, Rabat, Maroc \\ ${ }^{3}$ Centre National pour la Recherche Scientifique et Technique (CNRST-UATRS), Rabat, Maroc
}

\begin{abstract}
This paper reports a study on oxidative degradation and mineralization of pyrazinamide in an aqueous medium at $\mathrm{pH}=3$ and room temperature $\left(\approx 19^{\circ} \mathrm{C}\right)$ by the electro-Fenton process, using carbon felt as a cathode and platinum as an anode. The degradation/mineralization is assessed by the chemical oxygen demand by analyzing applied current intensity and concentration of $\mathrm{Fe}^{2+}$ catalyst. Thus, the main objective is to determine the optimal values of these parameters. Some stable intermediate products have been identified using highperformance liquid chromatography and liquid chromatography tandem mass spectrometry, which show the successive formation of the aromatic/cyclic organics and aliphatic intermediates. The second part of this work corresponds to the study of the biodegradability giving by the ratio: $\mathrm{BOD}_{5} / \mathrm{COD}$ during the mineralization of pyrazinamide by EF in order to examine the possibility of combining electro-Fenton with a biological posttreatment.
\end{abstract}

Keywords: Water treatment; pyrazinamide antibiotic; electro-Fenton process; oxidative degradation; mineralization; biodegradation.

\section{Introduction}

The treatment/removal of active pharmaceuticals and its degradation products from the environment have received great interest, given their negative impact on human health, on fauna and flora, So, they are important pollutants in surface waters ${ }^{1}$. In recent years due particularly to the advanced oxidation processes (AOPs) as alternative or complementary methods to conventional wastewater treatment techniques. Indeed, it is important to know that the byproducts are generally more toxic than the starting molecules, thus causing a real danger on the environment. Also, among the (AOPs), processes related to chemical oxidation in homogeneous phase processes $^{2,3}$, ozonation ${ }^{4}$, photochemical reactions ${ }^{5-8}$, photocatalysis ${ }^{9,10}$, direct and indirect electrochemical processes ${ }^{11-15}$, hybrid technique ${ }^{16}$ etc, are worth considering. AOPs, in fact, relies on an in situ a generation of hydroxyl radicals ${ }^{\circ} \mathrm{OH}$ which shows higher oxidizing power than the conventional oxidants $\mathrm{H}_{2} \mathrm{O}_{2}, \mathrm{Cl}_{2}, \mathrm{ClO}_{2}^{-}$or $\mathrm{O}_{3}$. These radicals can mineralize the organic and organometallic compounds either partially or entirely.

Some studies have shown that pyrazinamide antibiotic has a phototoxic potential to participate in several kinds of photochemical reactions ${ }^{8}$. In another study on the degradation of isoniazid and pyrazinamide antibiotics under UV radiation, $\mathrm{TiO}_{2}$ showed better photocatalytic activity than $\mathrm{ZnO}{ }^{17}$, undertook research to determine the forced degradation of pyrazinamide by various conditions such as acid, alkali, oxidation, thermal and photolytic ${ }^{18}$. Also, forced degradation study for assay method of rifampicin, isoniazid and pyrazinamide in combined pharmaceutical dosage form has recently been reported in the literature ${ }^{19}$.

In the domain of electro-chemistry, the effectiveness of "Electro-Fenton" (EF) process in the degradation of persistent and/or toxic organic pollutants including pharmaceuticals in aqueous medium was also demonstrated ${ }^{20-23}$. 
This process (electro-Fenton) is based on the in situ production of hydroxyl radicals (according to reaction (1)) in acidic medium ${ }^{24-26}$.

$$
\begin{aligned}
& \mathrm{H}_{2} \mathrm{O}_{2}+\mathrm{Fe}^{2+}+\mathrm{H}^{+} \rightarrow \cdot \mathrm{OH}+\mathrm{Fe}^{3+}+\mathrm{H}_{2} \mathrm{O} \\
& \mathrm{O}_{2}+2 \mathrm{H}^{+}+2 \mathrm{e}^{-} \rightarrow \mathrm{H}_{2} \mathrm{O}_{2} \\
& \mathrm{Fe}^{3+}+1 \mathrm{e}^{-} \rightarrow \mathrm{Fe}^{2+}
\end{aligned}
$$

The regeneration of $\mathrm{Fe}^{2+}$ (reaction (3)) from electro-reduction of $\mathrm{Fe}^{3+}$ produced by reaction (1) and the regeneration of $\mathrm{H}_{2} \mathrm{O}_{2}$ (reaction 2) also ensures the continuous formation of ${ }^{\circ} \mathrm{OH}$.

In an acidic medium ( $\mathrm{pH}$ about 3 ), the oxidizing power of the hydroxyl radical is very high $\left(\mathrm{E}^{\circ}\left({ }^{\circ} \mathrm{OH} / \mathrm{H}_{2} \mathrm{O}\right)=2.8 \mathrm{~V} / \mathrm{SHE}\right.$, and its reactivity is optimal. Under this condition, these hydroxyl radicals can attack any organic molecule present in the solution and the oxidative degradation leads to finally mineralization to $\mathrm{CO}_{2}$

Generally, during degradation/oxidation by AOPs, the biorefractory molecules degrade into small biodegradable molecules. This shows the possibility of combining the advanced oxidation process (Fenton or Photo-Fenton or Electro-Fenton) with the biological process to treat efficiently and economically aqueous solutions contaminated with persistent organic pollutants, as shown in the literature $27-32$

The present study shows the possibility of coupling electro-Fenton and a biological process for the effective removal of pyrazinamide from the water. The electrochemical reactor used in this study involves a carbon-felt cathode and a platinum anode. Several electrolysis experiments were carried out on aqueous solutions of pyrazinamide at a constant current intensity at $\mathrm{pH}=3$ and in the presence of $\mathrm{Fe}^{2+}$ catalyst. We study in this way, the effect of the applied current intensity and the concentration of $\mathrm{Fe}^{2+}$ (catalyst) on the kinetics of degradation and mineralization of pyrazinamide. The degradation was followed by changes in the concentration of pyrazinamide and mineralization of the treated solutions by monitoring the chemical oxygen demand (COD).

Methods of chromatographic analysis using highperformance liquid chromatography (HPLC) and liquid chromatography-mass spectrometry (LC/MSMS) have been used to identify the intermediate products. The biodegradability of pyrazinamide has assessed at various times during the electro-Fenton process in order to estimate the optimal time to introduce the biological process. The biodegradation tests were conducted using domestic wastewater, and the biodegradability is expressed by the $\mathrm{BOD}_{5} / \mathrm{COD}$ ratio ${ }^{33}$. This value gives information about the portion of organic materials present that can be aerobically degraded during five days.

\section{Experimental}

\section{Chemicals}

Pyrazinamide (PZA, Table 1) was obtained from Pharma 5. Ferrous sulfate, sodium sulfate, potassium chloride and sulfuric acid were obtained from Shangai Chemical Reagents Co. (Shangai, China). Acetonitrile (HPLC grade) was obtained from Carlo ERPA. The aqueous solutions used in all experiments were prepared with ultra-pure water obtained from a

\begin{tabular}{|c|c|c|c|c|}
\hline Compound & Structure & $\begin{array}{l}\text { Molecular } \\
\text { Weight }\end{array}$ & $\begin{array}{c}\text { wavelength } \\
\text { of } \\
\text { absorption }\end{array}$ & $\begin{array}{c}\text { Water } \\
\text { Solubility }\end{array}$ \\
\hline Pyrazinamide & & $123.115 \mathrm{~g} / \mathrm{mol}$ & $\begin{array}{c}\text { Range: } \\
\text { 200-400 nm }\end{array}$ & $\begin{array}{c}15000 \mathrm{mg} / \mathrm{L} \\
\left(\text { at } 25^{\circ} \mathrm{C} \text { ) }\right. \\
M E R C K \\
I N D E X \\
\text { (1996) }\end{array}$ \\
\hline
\end{tabular}
Millipore Milli-Q system.

Table 1. Proprieties of pyrazinamide molecule.

\section{The electrolytic system}

In order to carry out the electro-Fenton (EF) treatments, we employed Voltalab Potentiostat/Galvanostat instrument, type PGZ 100. Electrochemical tests were performed in an open cell of $250 \mathrm{~mL}$ capacity. A surface of platinum $(2.5 \mathrm{~cm} \times$ $2 \mathrm{~cm}$ ) was used as an anode, and three-dimensional surface of carbon felt $(6 \mathrm{~cm}$ x $5 \mathrm{~cm}$ x $0.5 \mathrm{~cm}$, CarboneLorraine) as a cathode. The anode was placed in the center of the electrolyte just in front of the cathode.
The concentrations of the components of aqueous solutions for the electrolysis were: $0.3 \mathrm{mM}$ pyrazinamide, $0.5 \mathrm{mM} \mathrm{Fe}^{2+}$ and $0.05 \mathrm{M} \mathrm{Na}_{2} \mathrm{SO}_{4}$ at $\mathrm{pH}=3$ (each one in distilled water with a volume of $200 \mathrm{ml}$, constituting thus, the solution to be treated)). The temperature was kept at (temperature $\approx 19^{\circ} \mathrm{C}$ ). The applied current intensity was in the range of 60 $\mathrm{mA}$ to $400 \mathrm{~mA}$. The solutions were subjected to constant agitation to ensure mass transport to the electrodes. 


\section{Analytical procedures}

Chemical oxygen demand (COD) is as method to monitor the degradation of pyrazinamide in treated solutions. The evaluation of COD was carried out by using spectrophotometer DR/125 (Hach Company USA) by the dichromate method. An appropriate amount of sample was introduced into a solution containing potassium dichromate, sulfuric acid and mercuric sulfate, was used a range of 0 to $150 \mathrm{mg} \mathrm{O} \mathrm{O}_{2}$ $\mathrm{L}^{-1}$ of a digestion solution. The mixture solution was then incubated for 120 minutes at $150{ }^{\circ} \mathrm{C}$ in Lovibond ${ }^{\circledR}$ COD VARIO photometers. Variation in time of concentration of pyrazinamide was followed by reverse-phase high-performance liquid chromatography (HPLC) using a Waters 2695 coupled photodiode-array detector (PDA) 2998, selecting at optimum wavelengths of $270 \mathrm{~nm}$. Data acquisition was performed through the Empower 2 Software data registration, and fitting with a Thermohypersil C 18,5 $\mu \mathrm{m}, 25 \mathrm{~cm}, 4.6 \mathrm{~mm}$ (i.d.), column at $40^{\circ} \mathrm{C}$. The analyses on $100 \mu \mathrm{L}$ sample volume were performed isocratically using a phosphate buffer ( $\mathrm{pH} 2.2) /$ acetonitrile $46: 54$ (v/v) mixture as a mobile phase at a flow rate of $1.5 \mathrm{~mL} \mathrm{~min}^{-1}$.

The stable intermediate products formed during electro-Fenton treatment of pyrazinamide were identified under the same operating conditions using liquid chromatography-mass spectrometry LC/MSMS (AB Sciex - API 3200 QTRAP®, instrument triple quadrupole) by operating in the negative ion mode. Data acquisition was performed with analysis software ${ }^{\circledR}$ Version 1.5. Reaction aliquots were infused directly into the ion source at a speed of $20 \mu \mathrm{L} / \mathrm{min}$ using a micro-syringe (Hamilton Company, Reno, NV, USA). Typical conditions of ESI are: heated capillary temperature, $300^{\circ} \mathrm{C}$; sheath gas $\left(\mathrm{N}_{2}\right)$ at a flow velocity of $20 \mathrm{~mL} / \mathrm{min}$; spray voltage $-4.5 \mathrm{kV}$; gas flow and the nebulizing gas curtain of the apparatus were adjusted at 30 and 10 $\mathrm{ml} / \mathrm{min}$, respectively.

The BOD was measured by an OxiDirect, by using respirometric evaluation method in 5 days $\left(\mathrm{BOD}_{5}\right)$ at a temperature of $20^{\circ} \mathrm{C}$ in dark conditions. $\mathrm{pH}$ was adjusted between 6.5 and 7.5 , and $\mathrm{N}$-allylthiourea was used as a nitrification inhibitor. $\mathrm{KOH}$ pellets were added to the bottles to trap $\mathrm{CO}_{2}$.

In order to degrade the PZA molecule biologically, we have used domestic wastewater obtained from the National Office of Electricity and Drinking Water, Rabat, Morocco.

\section{Results and discussion}

Influence of applied current on the oxidative degradation kinetics of pyrazinamide aqueous solution.

The important influencing factors on the electroFenton process are the intensity of applied current, catalyst concentration, solution $\mathrm{pH}$ and background electrolyte. In many studies, it has been clearly shown that the optimal $\mathrm{pH}$ value is about $3^{34-36}$ and sodium sulfate acts as the best-supporting electrolyte ${ }^{21}$.

The effect of applied current value on the oxidative degradation of pyrazinamide by hydroxyl radicals ${ }^{\circ} \mathrm{OH}$ was studied for $200 \mathrm{~mL}$ of $0.34 \mathrm{mM}$ pyrazinamide solution with $0.1 \mathrm{mM} \mathrm{Fe} \mathrm{F}^{2+}$ at $\mathrm{pH}=3$, during EF process (Fig. 1).

The use of these data above has allowed us to determine the optimum value of the applied current for which the oxidation of pyrazinamide considered would be kinetically favored.

Thus, the evolution of the concentration of pyrazinamide as a function of the electrolysis time is followed by high-performance liquid chromatography (HPLC).

Increasing the applied current intensity from 60 to $400 \mathrm{~mA}$ leads to accelerated degradation kinetics of pyrazinamide. This demeanor can be explained by the acceleration of the rate of electrochemical reactions (2) and (3) leading to the generation of more ${ }^{\circ} \mathrm{OH}$ radicals (Fenton reaction at $\mathrm{pH}=3(1)$ ).

The complete disappearance of pyrazinamide was checked at 60, 40, 20 and $25 \mathrm{~min}$ for 60, 100, 300 and $400 \mathrm{~mA}$ current values, respectively. These results show that the degradation rate of pyrazinamide was not significantly changed after $300 \mathrm{~mA}$ current. Therefore, the optimal current value is $300 \mathrm{~mA}$. Additional increase in current intensity led to decreasing oxidative efficiency of pyrazinamide while making long treatment time for the complete disappearance of pyrazinamide. This behavior is confirmed in (the inset of Figure 1) which demonstrates that the apparent rate constants (Kapp) for the oxidation of pyrazinamide by ${ }^{\circ} \mathrm{OH}$ follows pseudo-first-order reaction kinetics. Indeed, we may find similar results in the literature, where there are deductions and ascertainments, which tend to us ${ }^{21}$. 


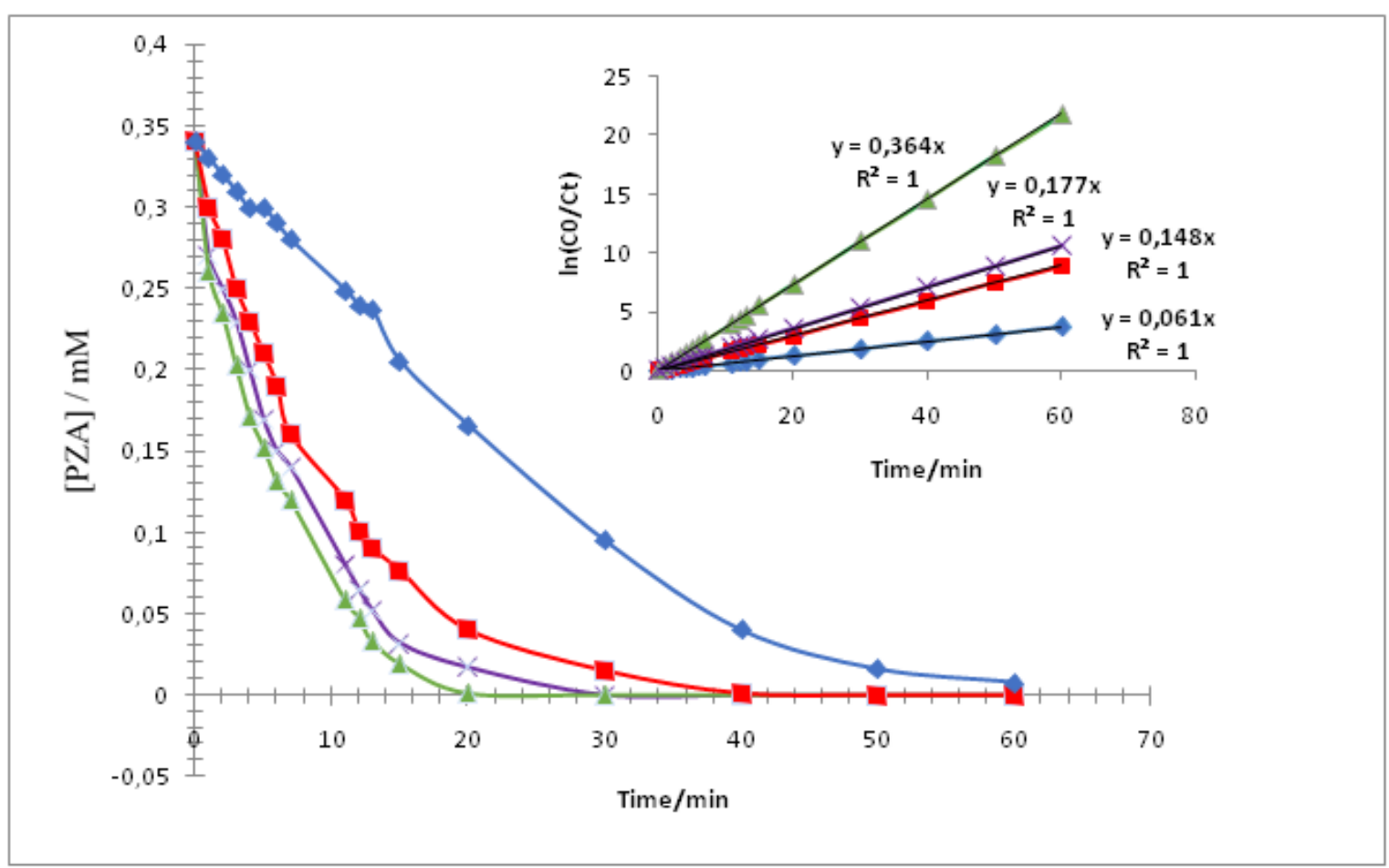

Figure 1. Effect of applied current on degradation of pyrazinamide during EF treatment at $\mathrm{pH} 3,[\mathrm{PZA}]_{0}=0.34$ $\mathrm{mM}$, with $\left[\mathrm{Fe}^{2+}\right]=0.1 \mathrm{mM}, \mathrm{I}(\mathrm{mA})=60(-\downarrow-), 100(-\mathbf{m -}), 300(-\boldsymbol{\Delta}-)$ and $400(-\times-)$

The apparent rate constant values (Kapp) for the oxidation of pyrazinamide correspond to the slopes of

the linear, $\ln \left(\mathrm{C} / \mathrm{C}_{0}\right)$, were plotted as a function versus time (Table 2).

Table 2. Apparent rate constants Kapp obtained during the EF treatment at various applied current intensity for pyrazinamide.

\begin{tabular}{|c|c|c|c|}
\hline $\begin{array}{c}\text { Initial PZA } \\
\text { concentration }\end{array}$ & $\begin{array}{c}\text { Fe }^{2+} \\
\text { concentration }\end{array}$ & $\begin{array}{c}\text { Applied current } \\
\text { intensity }\end{array}$ & $\begin{array}{c}\text { Apparent rate constant } \\
\text { Kapp }\end{array}$ \\
\hline $\mathbf{( m M )}$ & $(\mathrm{mM})$ & $(\mathrm{mA})$ & $\left(\mathrm{min}^{-1}\right)$ \\
\hline $\mathbf{0 . 3 4}$ & 0.10 & 60 & 0.0618 \\
\hline $\mathbf{0 . 3 4}$ & 0.10 & 100 & 0.1486 \\
\hline $\mathbf{0 . 3 4}$ & 0.10 & 300 & 0.3645 \\
\hline $\mathbf{0 . 3 4}$ & 0.10 & 400 & 0.1776 \\
\hline
\end{tabular}

The Kapp value at $400 \mathrm{~mA}$ is lower as compared to at $300 \mathrm{~mA}$. Higher applied current intensity could be responsible for the acceleration of wasting reactions such as $4 \mathrm{e}^{-}$a reduction of $\mathrm{O}_{2}$ leading to $\mathrm{H}_{2} \mathrm{O}$ (reaction (4)) instead of $\mathrm{H}_{2} \mathrm{O}_{2}$, the evolution of $\mathrm{H}_{2}$ (reaction (5)) and the oxidation of $\mathrm{H}_{2} \mathrm{O}_{2}$ (reaction (6)).

$\mathrm{O}_{2}+4 \mathrm{e}^{-}+4 \mathrm{H}^{+} \rightarrow 2 \mathrm{H}_{2} \mathrm{O}$

$2 \mathrm{H}_{2} \mathrm{O}+2 \mathrm{e}^{-} \rightarrow \mathrm{H}_{2}+2 \mathrm{OH}^{-}$

$\mathrm{H}_{2} \mathrm{O}_{2} \rightarrow \mathrm{O}_{2}+2 \mathrm{H}^{+}+2 \mathrm{e}^{-}$

The increase in the Kapp values from 0.061 to 0.364 $\mathrm{min}^{-1}$ agrees with the expected enhancement of the production of ${ }^{\circ} \mathrm{OH}$ radicals during Fenton reaction (3).

Influence of experimental parameters on the mineralization kinetics of pyrazinamide aqueous solution
Several experiments were performed with different applied current values in the presence of 0.1 $\mathrm{mM} \mathrm{Fe}^{2+}$ to study the mineralization kinetics of aqueous pyrazinamide through electro-Fenton process (Fig. 2(a)).

We noticed that during electrolysis the COD decreases in a continuous way indicating the degradation of pyrazinamide (initially put in solution) as well as its degradation products. At high electrolysis times, COD reaches values very weak, showing the complete mineralization of the organic solution studied. For example, for the case of the intensity of applied current equal to $300 \mathrm{~mA}$, the COD decreases and reaches a corresponding value at an $81.63 \%$ mineralization rate after 6 hours of electrolysis. 


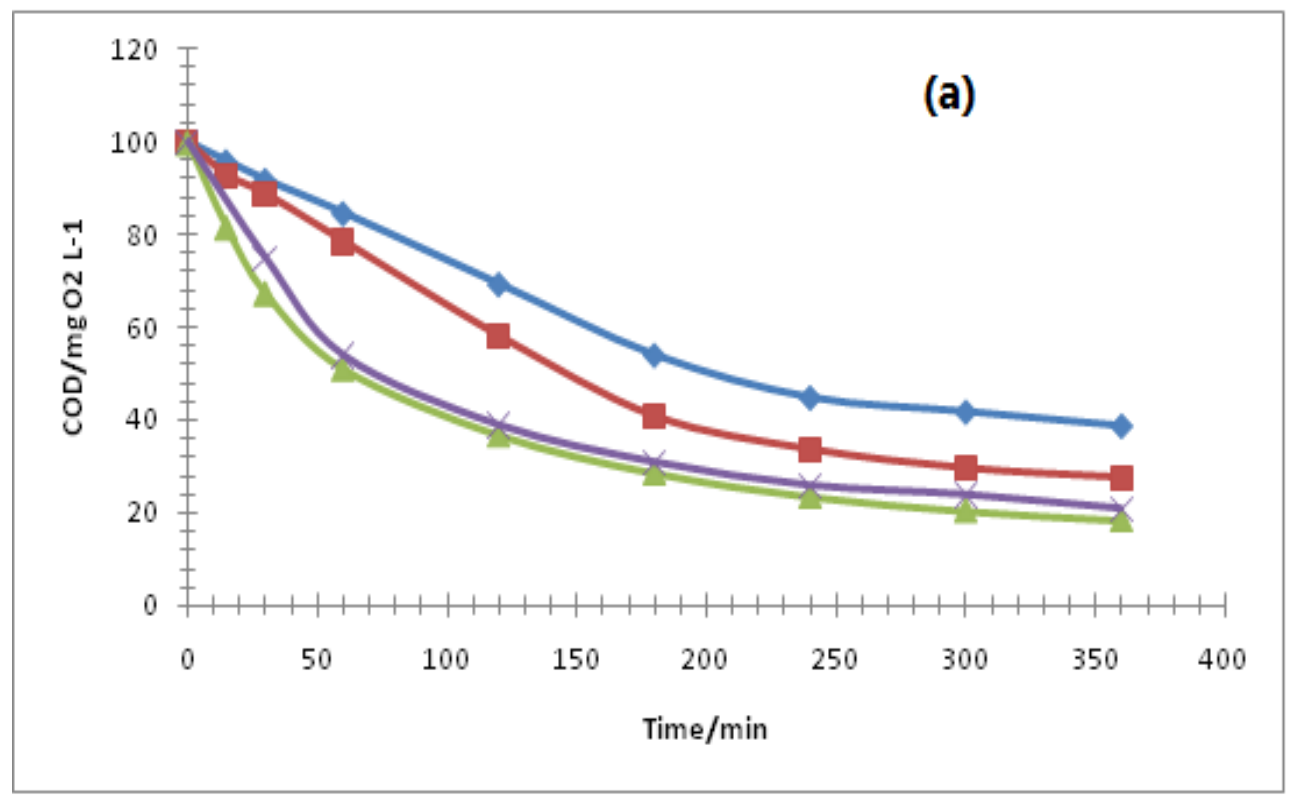

Figure 2 (a). Effect of applied current on pyrazinamide $(0.34 \mathrm{mM})$ mineralization during electro-Fenton treatment at $\mathrm{pH} 3,0.05 \mathrm{M} \mathrm{Na}_{2} \mathrm{SO}_{4}$ at room temperature in $0.05 \mathrm{M} \mathrm{Na}_{2} \mathrm{SO}_{4}$ solution. $\left[\mathrm{Fe}^{2+}\right](\mathrm{mM})=0.1$. I $(\mathrm{mA})=$

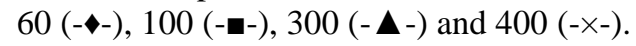

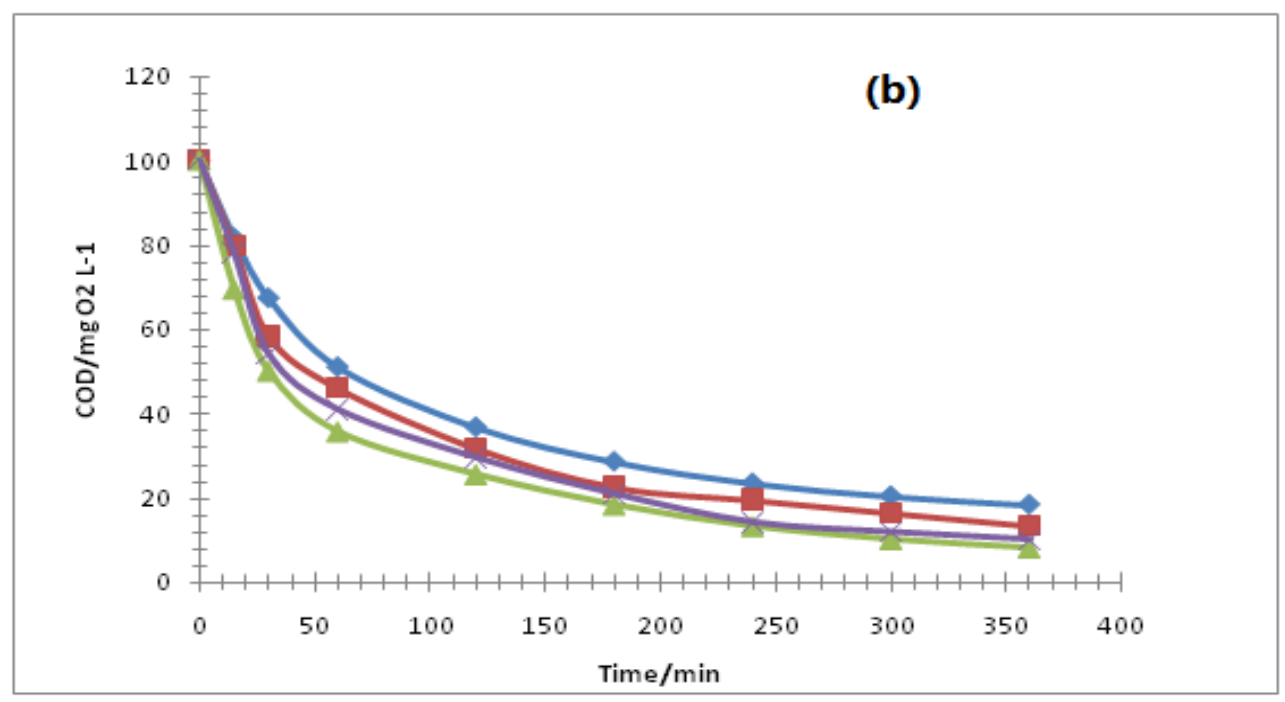

Figure 2 (b). Effect of catalyst concentration on pyrazinamide $(0.34 \mathrm{mM})$ mineralization during electro-Fenton treatment at $\mathrm{pH} 3,0.05 \mathrm{M} \mathrm{Na}_{2} \mathrm{SO}_{4}$ at room temperature in $0.05 \mathrm{M} \mathrm{Na}_{2} \mathrm{SO}_{4}$ solution. I $(\mathrm{mA})=300 .\left[\mathrm{Fe}^{2+}\right](\mathrm{mM})=$ $0.1(-\bullet), 0.2(-\mathbf{-}-), 0.5(-\mathbf{\Delta}-)$ and $0.8(-\times-)$.

Figure 2 (a) shows that the COD decay rate increases by increasing the applied current intensity from 60 to $400 \mathrm{~mA}$. After $300 \mathrm{~mA}$ value, an increase in the applied current intensity did not give any positive effect on COD abatement rate and therefore led to a weak COD removal kinetics due to the enhancement of wasting reactions (4) that may damage a generation of Fenton's reagent.

Therefore, the applied current intensity of 300 $\mathrm{mA}$ can be considered as the optimal applied current intensity for a maximum mineralization rate for pyrazinamide. Whereas, the mineralization degrees of pyrazinamide solution after 6 hours of electro-Fenton treatment was $61.22 \%, 72.45 \%, 81.63 \%$ and $79 \%$ for $60,100,300 \mathrm{~mA}$ and $400 \mathrm{~mA}$, respectively.
Several experiments have been carried out by changing the catalyst concentrations in the range of $0.1-0.8 \mathrm{mM}$ at $300 \mathrm{~mA}$ during the treatment with EF (results in Fig. 2(b)).

COD decay rate increases by increasing the amount of $\mathrm{Fe}^{2+}$ catalyst concentration from 0.1 to $0.5 \mathrm{mM}$. After a certain value, as $0.8 \mathrm{mM}$, the removal rate of pyrazinamide solution decreases, which can be explained by the parasitic reaction between $\mathrm{Fe}^{2+}$ and hydroxyl radicals' reaction $(7)^{37}$. We can find similar results in the literature, where there are deductions and ascertainments who approach us ${ }^{20}$. It can be the said based on the results that the concentration of the catalyst $\left(\mathrm{Fe}^{2+}\right)$ is very significant in the electro-Fenton process. 


$$
\mathrm{Fe}^{2+}+{ }^{\circ} \mathrm{OH} \rightarrow \mathrm{Fe}^{3+}+\mathrm{OH}^{-}
$$

To further clarify the effect of applied current on the mineralization of the treated solution by the EF process, we calculated the efficiency of the mineralization current (instantaneous current efficiency (ICE)), at different electrolysis times.

As shown in (Fgure3), ICE can be calculated by the values of COD using the relation (8), as expressed below ${ }^{22}$ :

$$
\mathrm{ICE}=\frac{\left(\mathrm{COD}_{0}-\mathrm{COD}_{\mathrm{t}}\right) \mathrm{FV}}{8 \mathrm{It}}
$$

Where, $\mathrm{COD}_{0}$ refers to the starting COD value, $\mathrm{COD}_{\mathrm{t}}$ refers to the final $\mathrm{COD}$ value, $\mathrm{I}$ is the applied current (A), $\mathrm{F}$ is the Faraday constant $(96.487 \mathrm{C}$ mole $\left.{ }^{-1}\right), t$ is the treatment time $(\mathrm{s})$, and $\mathrm{V}$ is the volume of the solution $(\mathrm{L})$.

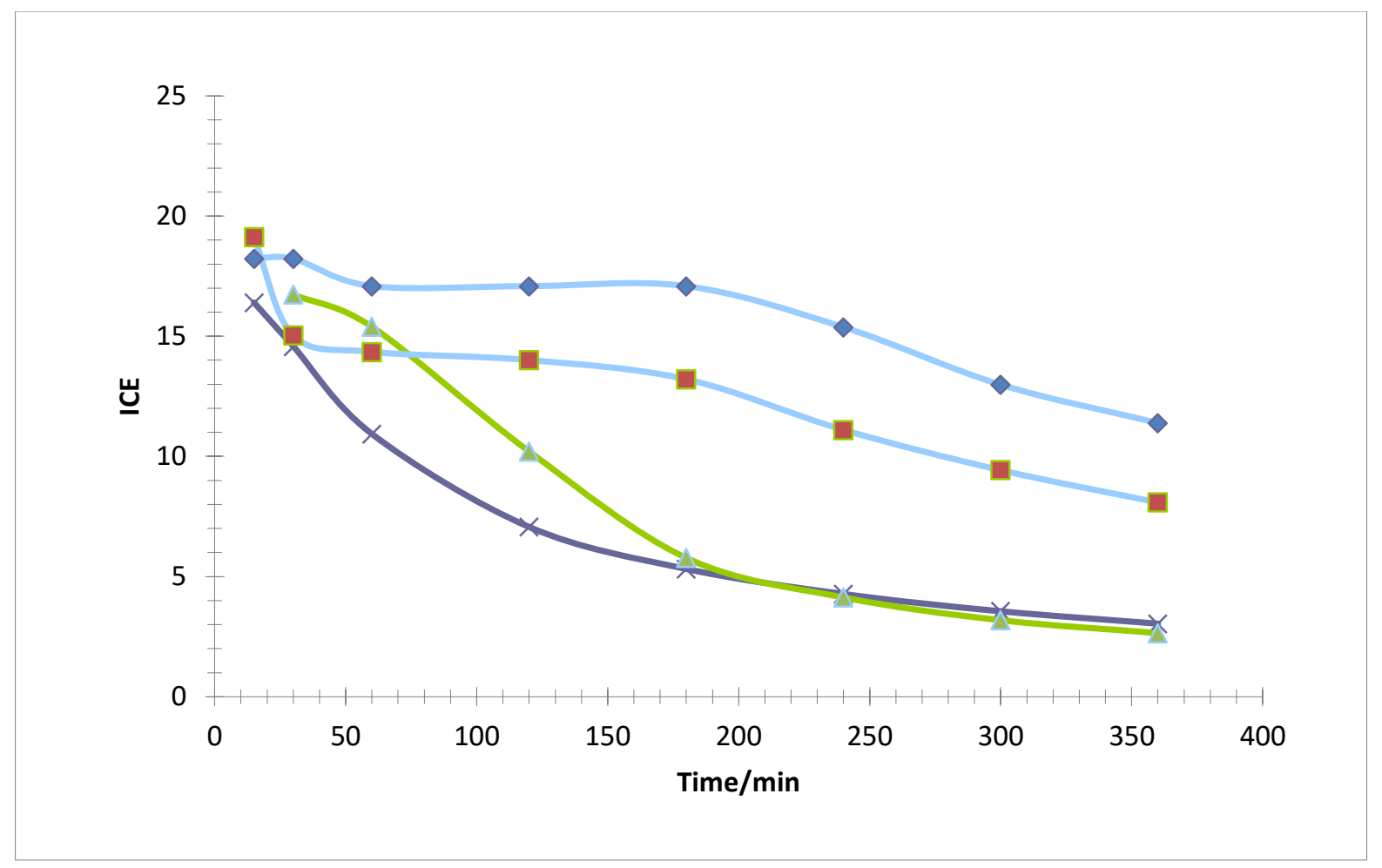

Figure 3. Instantaneous current efficiency change during the electro-Fenton process, $\left[\mathrm{Fe}^{3+}\right]=0.1 \mathrm{mM},\left[\mathrm{Na}_{2} \mathrm{SO}_{4}\right]$ $=0.05 \mathrm{M}, \mathrm{V}=200 \mathrm{ml}, \mathrm{I}(\mathrm{mA})=60(-\downarrow-), 100(-\mathbf{-}-), 300(-\boldsymbol{\Delta}-)$ and $400\left(-\mathbf{x}_{-}\right)$.

Better ICE\% values were obtained for $60 \mathrm{~mA}$ followed by $100 \mathrm{~mA}$, reaching 17.08 and $14.35 \%$, respectively. ICE increases with the decrease in applied current that can be related to a decrease in the concentration of aromatic/cyclic organic products in aqueous solution and the formation of short-chain carboxylic acids. It is noteworthy that the acids resist the mineralization and enhance the parasitic reactions (4) and (7) which, under the mentioned conditions, become dominant ${ }^{22}$, which might harm the generation of Fenton's reagent.

Influence of pyrazinamide concentration on the mineralization rate in aqueous solution

The mineralization removal values were investigated by using different pyrazinamide concentrations under the optimal conditions, as shown in Fig. 4.

The oxidation efficiency of the EF process was evaluated using different pyrazinamide concentrations under the optimal conditions in this work. Fig. 4 shows the effect of different initial pyrazinamide concentrations of $0.22,0.30$ and $0.41 \mathrm{mM}$. In all the cases, the pyrazinamide decreased as a function of time. The COD removals were $94 \%$, $87 \%$ and $86 \%$ respectively for the previous concentrations of the antibiotic solutions. It can be explained that in this case, the further increase in pyrazinamide concentration causes an increment in the number of collisions between the pyrazinamide molecules with themselves: nevertheless, the probability of collisions between pyrazinamide with $\cdot \mathrm{OH}$ decreases. 


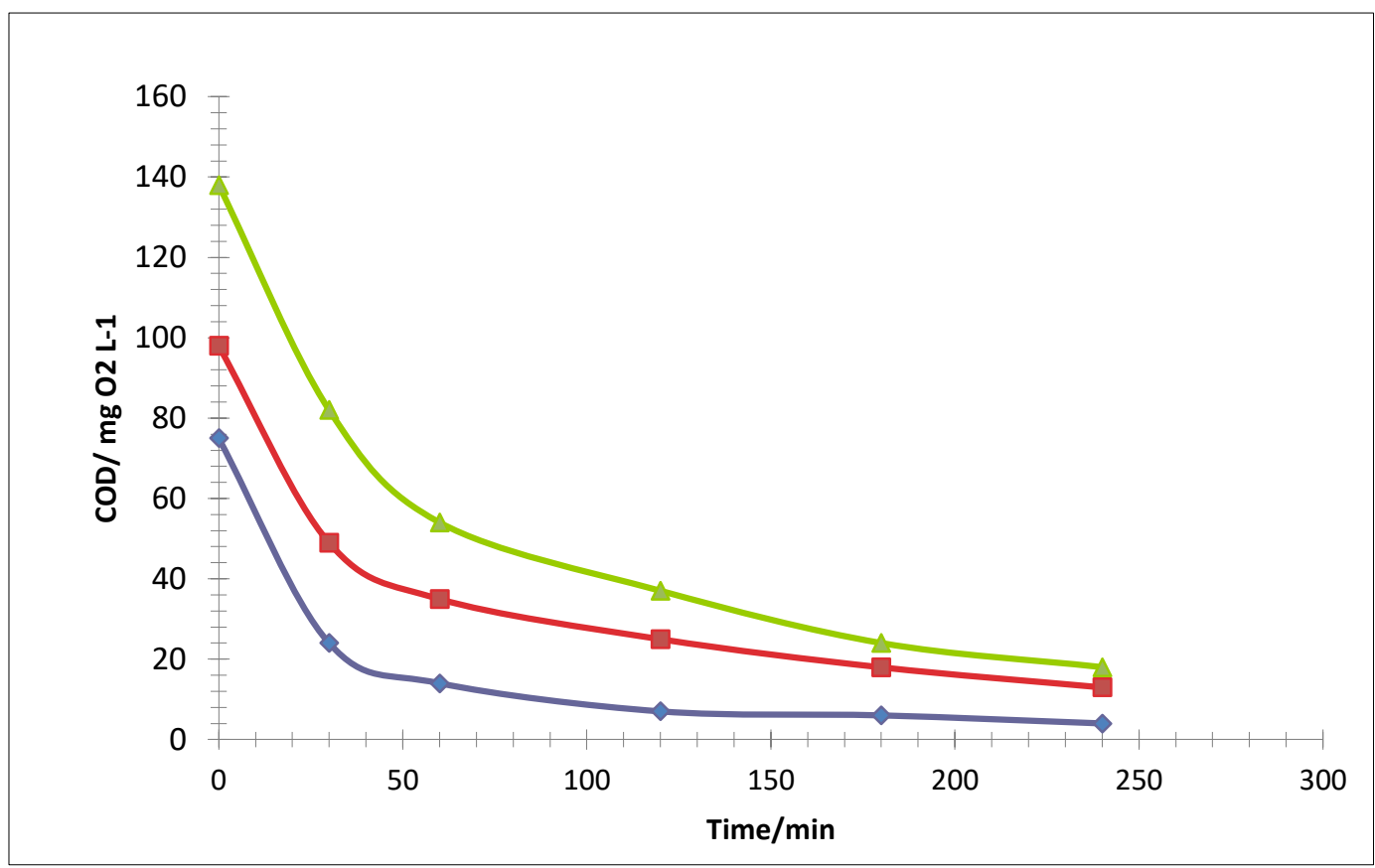

Figure 4. Effect of different pyrazinamide concentrations, for $0.22(-\downarrow-), 0.3(-\mathbf{-}-)$ and 0.41 .mM (- $\mathbf{\Delta}-)$ solutions, on PZA mineralization during electro-Fenton under the conditions: $\left[\mathrm{Fe}^{3+}\right]=0.5 \mathrm{mM}\left[\mathrm{Na}_{2} \mathrm{SO}_{4}\right]=0.05 \mathrm{M}, 300$ $\mathrm{mA}$ and $\mathrm{V}=200 \mathrm{ml}$.

\section{Identification of the reaction intermediates}

We identified the stable intermediate products formed during treatment using HPLC and LC/MS-MS analyses. The obtained results are taken in the first 1 $\mathrm{h}$ (4 min, $8 \mathrm{~min}, 15 \mathrm{~min}$ and $1 \mathrm{~h}$ ) of electrolysis during
electro-Fenton process showed an increasing disappearance of pyrazinamide and formation of some aromatic and aliphatic intermediate products. The concentration of these intermediate products goes to maxima and then decrease until full disappearance.

Table 3 represents the identified intermediates products, while HPLC chromatograms and mass spectra of these intermediate products are given in Figures 5 and 6, respectively.

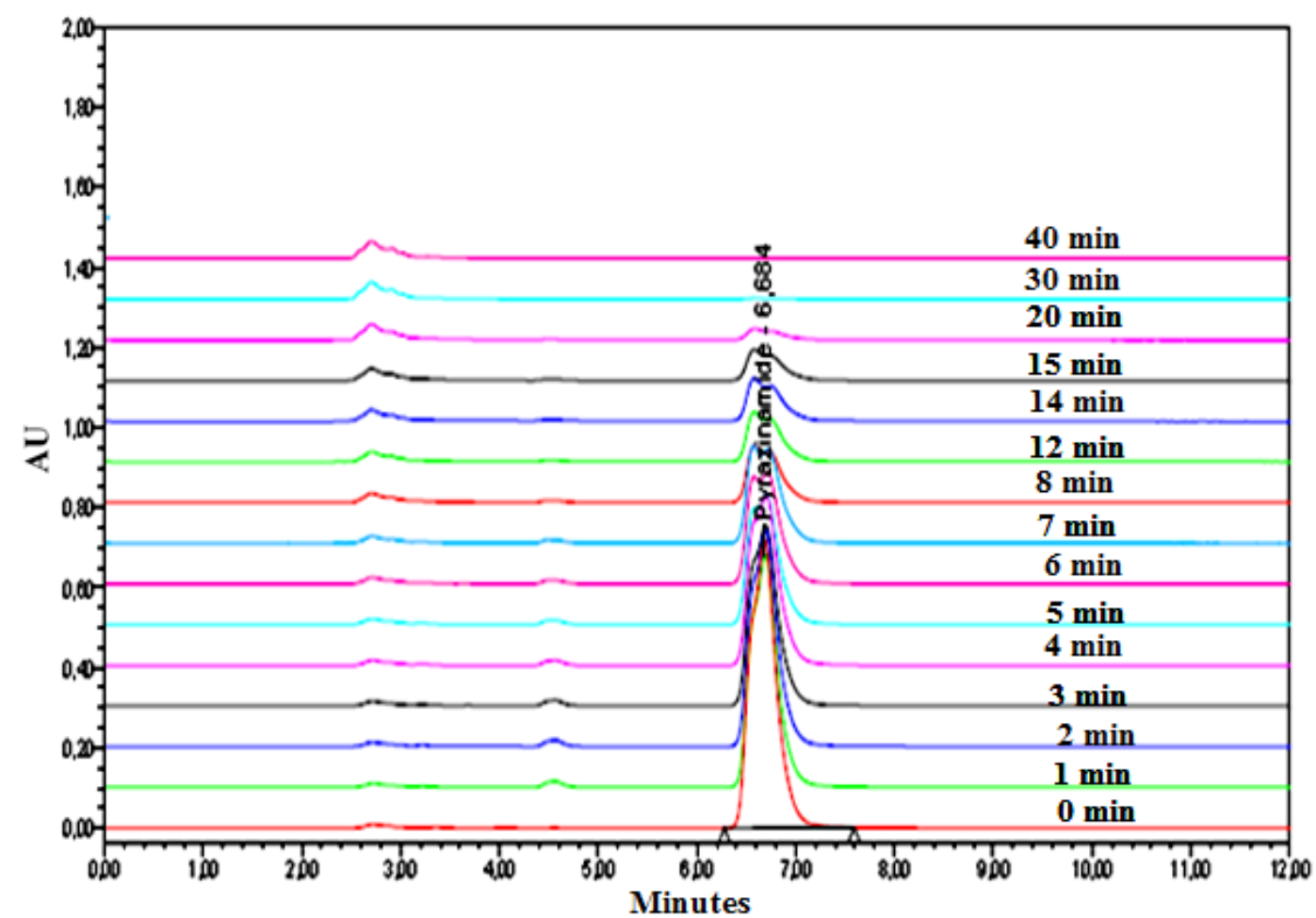

Figure 5. Chromatograms showing the decrease of the existence of pyrazinamide in the solution during the first $40 \mathrm{~min}$ of treatment by electro-Fenton process. $\left[\mathrm{Fe}^{2+}\right]=0.5 \mathrm{mM}, \mathrm{I}=300 \mathrm{~mA},\left[\mathrm{Na}_{2} \mathrm{SO}_{4}\right]=0.05 \mathrm{M}, \mathrm{V}=200 \mathrm{ml}$. 

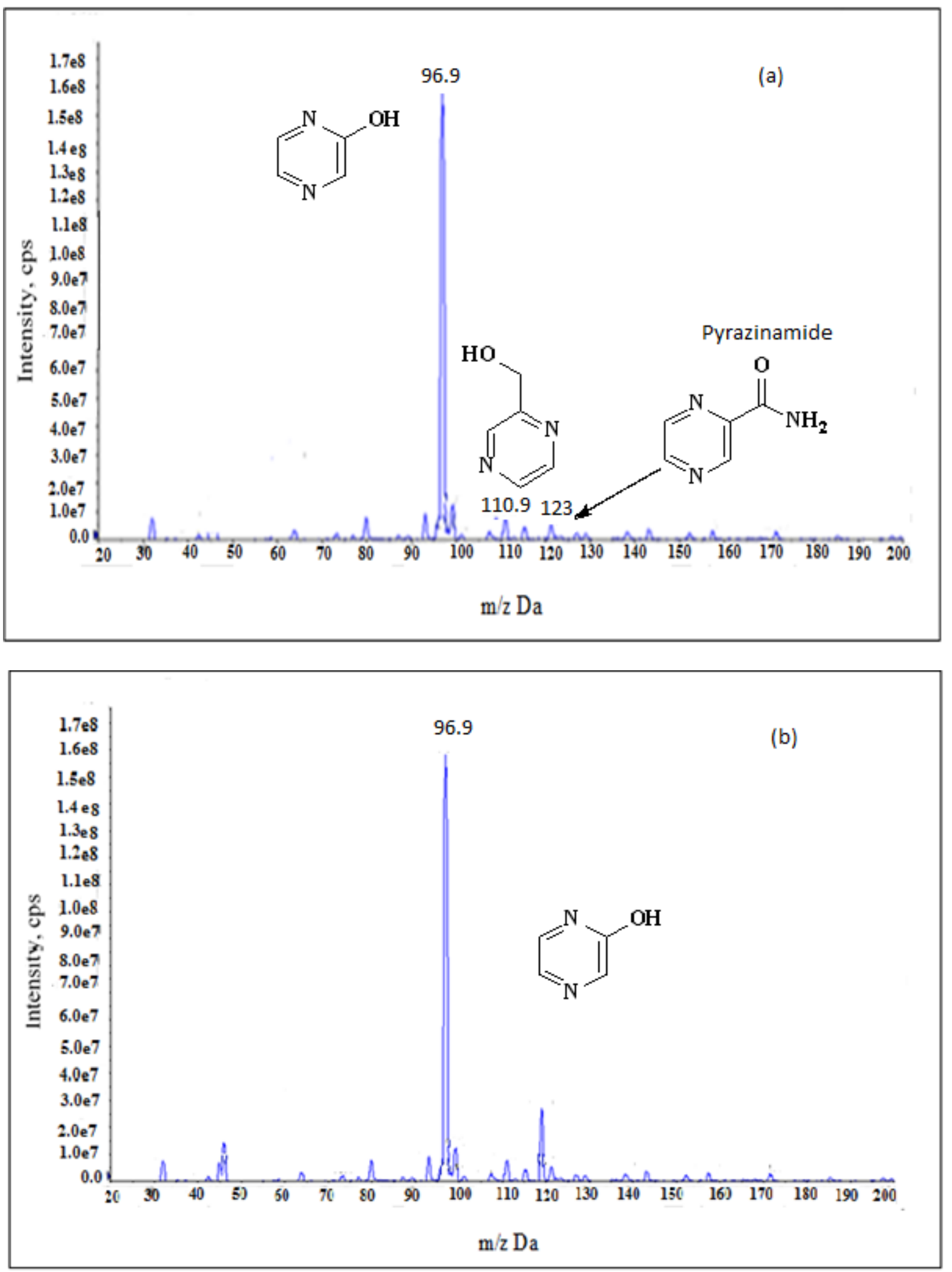

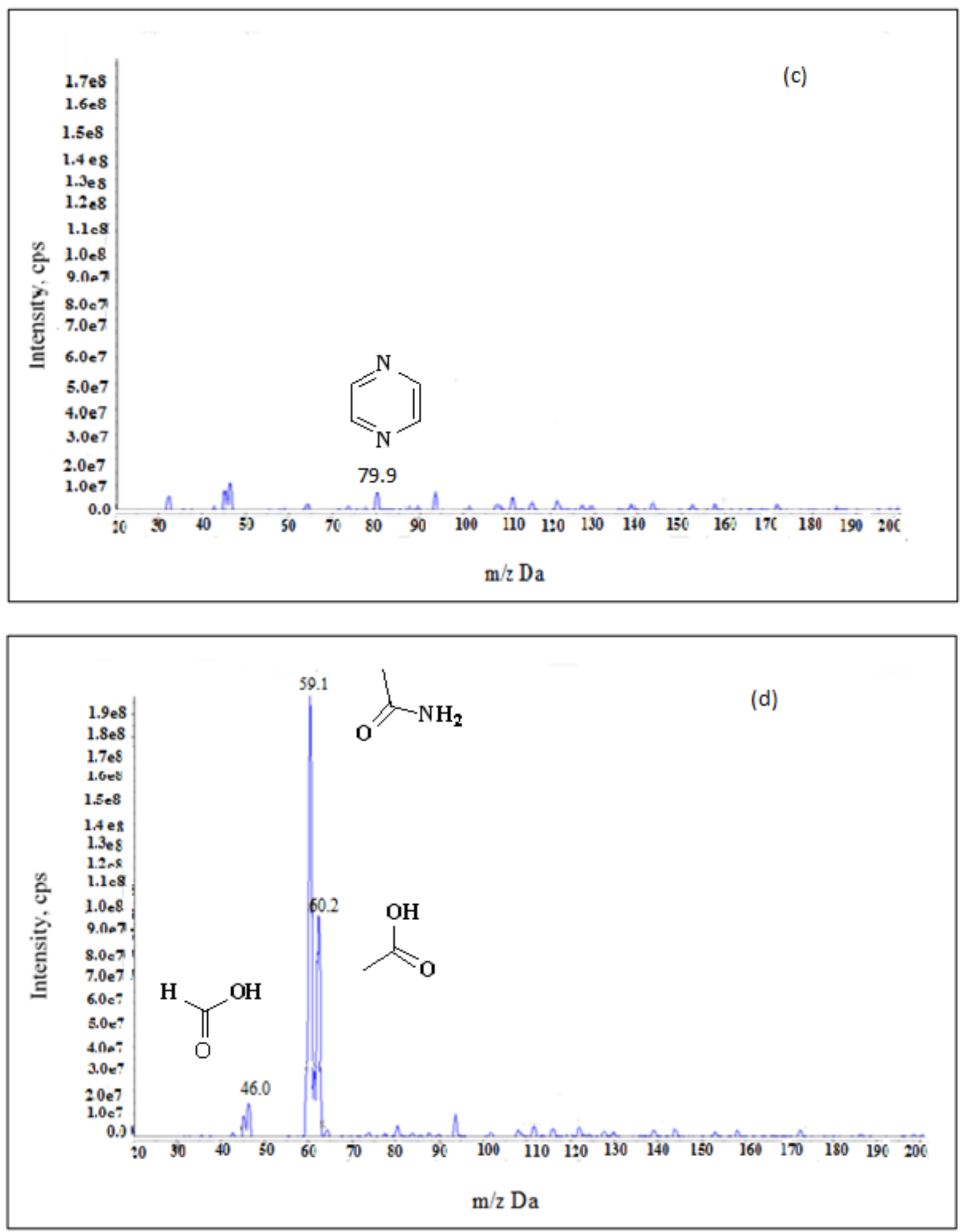

Figures 6. (a, b, c, d) Mass spectra of intermediate products present in the solution during $1 \mathrm{~h}$ of mineralization by electro-Fenton process of pyrazinamide. $\left[\mathrm{Fe}^{2+}\right]=0.5 \mathrm{mM}, \mathrm{I}=300 \mathrm{~mA},\left[\mathrm{Na}_{2} \mathrm{SO}_{4}\right]=0.05 \mathrm{M}, \mathrm{pH} 3$. 
Table 3. The intermediates identified by LC/MS-MS during the degradation of pyrazinamide by electro-Fenton treatment.

\begin{tabular}{|c|c|c|c|c|}
\hline Intermediates & Chemical formula & Molecule name & $\mathrm{m} / \mathrm{z}$ & References \\
\hline (1) & HO & pyrazin-2-ylmethanol & 110.1 & 8,17 \\
\hline (2) & $\mathbf{O H}$ & pyrazin-2-ol & 96.9 & 17 \\
\hline (3) & & pyrazine & 79.9 & 8,17 \\
\hline (4) & & Acetamide & 59.9 & 17 \\
\hline (5) & & Formic acid & 45.9 & 17 \\
\hline (6) & & Acetic acid & 61.0 & 17 \\
\hline
\end{tabular}

\section{Biodegradability study}

Investigation of biodegradation and mineralization rates during $\mathrm{EF}$ treatments of the samples are described in Fig. 7 at constant current intensity of $300 \mathrm{~mA}$ and a catalyst $\left(\mathrm{Fe}^{2+}\right)$ concentration of $0.5 \mathrm{mM}$.

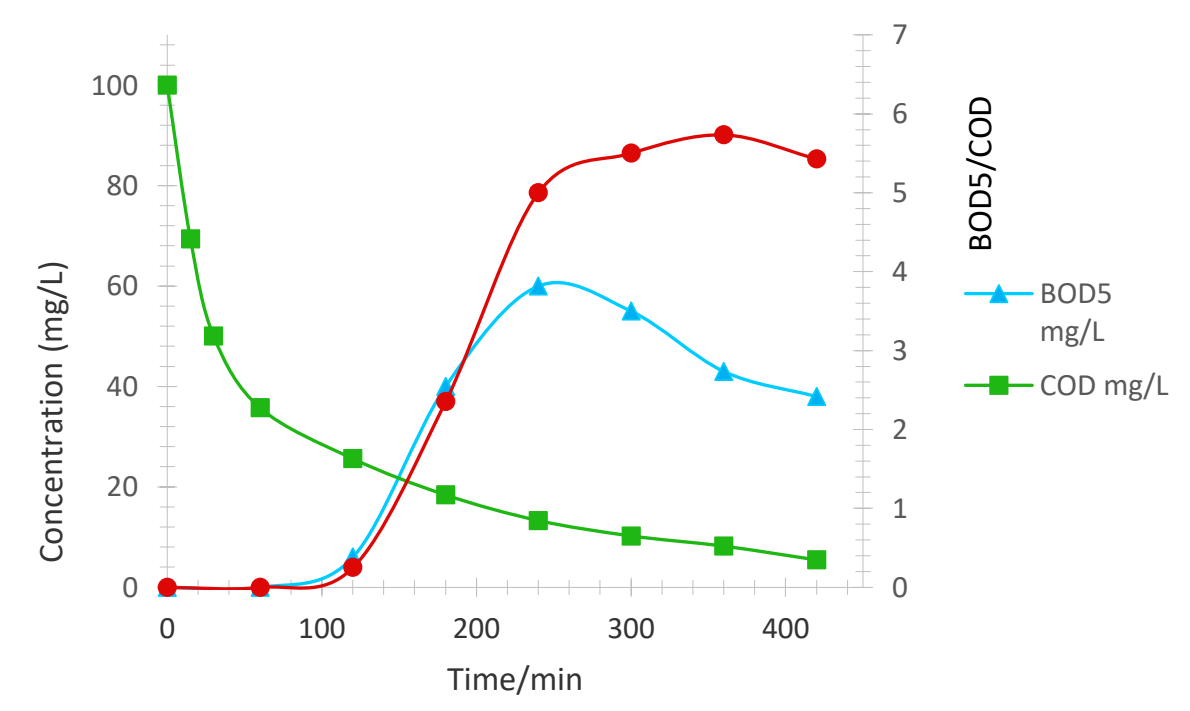

Figure 7. Biodegradability evolution $\left(\mathrm{BOD}_{5} / \mathrm{COD}\right.$ ratio) and mineralization evolution during the treatment by $\mathrm{EF}$ at $\mathrm{I}=300 \mathrm{~mA}$ and with a concentration of $\mathrm{Fe}^{2+}$ of $0.5 \mathrm{mM}$.

These results show that untreated pyrazinamide is non-biodegradable with $\mathrm{BOD}_{5} / \mathrm{COD}$ ratio is equal to zero. Likewise, this ratio remains zero during 100 minutes of treatment, indicating that the primary pyrazinamide degradation products are also nonbiodegradable. After this time, the biodegradability 
increases gradually, and at $\mathrm{t}=180$ minutes ( 3 hours) of electrolysis, the $\mathrm{BOD}_{5} / \mathrm{COD}$ ratio reaches the value 2.4 which indicates that the solution becomes biodegradable as is known in the literature ${ }^{38}$. Finally, during the times from 180 to $420 \mathrm{~min}$, the reaction intermediates keep reacting with the ${ }^{\circ} \mathrm{OH}$ radicals, in fact significantly enhancing the biodegradability to 5.43 .

Feasibility of the coupling of the advanced oxidation process (EF) with the biological post treatment

The results of the degradation/mineralization and biodegradability studies show that the pyrazinamide is non-biodegradable, but it is quickly oxidized by ${ }^{\circ} \mathrm{OH}$ and is completely degraded after 20 minutes of EF treatment (Fig. 1) and gives rise to the formation aromatic by-products ((1), (2) and (3), Table 3). These aromatic products are also nonbiodegradable, quickly oxidized by ${ }^{\circ} \mathrm{OH}$ and are completely degraded into short-chain aliphatic byproducts ((4), (5), (6), Table 3). These aliphatics resist at the mineralization because they are difficult to oxidize by ${ }^{\circ} \mathrm{OH}$, but perfectly biodegradable by the microorganisms of wastewater as is known in the literature ${ }^{37}$.

Moreover, it is interesting to note that globally there are two different stages during EF treatment: the first step of 0 to 3 hours and the second of 3 to 7 hours of electrolysis. During the first 3-hour stage, a significant rate $(82 \%)$ of COD abatement is reached, while the remaining $18 \%$ require a much longer period ( 4 hours) to be mineralized in $\mathrm{CO}_{2}+\mathrm{H}_{2} \mathrm{O}$ during this period. This is explained by the fact that the first treatment step corresponds to the degradation of the aromatic products (pyrazinamide and its byproducts (1), (2) and (3)) by ${ }^{\circ} \mathrm{OH}$ which is done with a fast kinetics and the second stage corresponds to the degradation of the aliphatic by-products that are difficult to mineralize in $\mathrm{CO}_{2}$ by ${ }^{\circ} \mathrm{OH}$.

During this second stage of the EF treatment, much more energy was consumed unnecessarily because of the parasitic reactions (4) and (7) which consume the ${ }^{\circ} \mathrm{OH}$ reagent as was demonstrated previously in the study of the applied current effect on the mineralization of the solution treated by the EF process.

These two steps can be illustrated by Figure 8 giving the global diagram of degradation/mineralization of pyrazinamide in an aqueous medium and the successive formation of recalcitrant and biodegradable organic reaction intermediates using EF process as treatment under optimal conditions $\left(300 \mathrm{~mA}\right.$ and $\left.\left[\mathrm{Fe}^{2+}\right]=0.5 \mathrm{mM}\right)$. Indeed, the intermediates are in agreement with the fragments found in mass spectrometry.

Based on these results, it seems feasible to switch the EF process to a biological process after $3 \mathrm{~h}$ of electrolysis. Indeed, on the one hand, after $7 \mathrm{~h}$ of electrolysis we obtained a $97 \%$ abatement rate, and on the other hand, we found a rate of $82 \%$ after 3 hours of EF treatment. Thus, by adopting the biological method after $3 \mathrm{~h}$ of treatment by the EF method, we will economize relative energy to $4 \mathrm{~h}$ of electrolysis, this means more than half of the total treatment time $(7 \mathrm{~h})$ required for complete mineralization. in $\left(\mathrm{CO}_{2}+\right.$ $\mathrm{H}_{2} \mathrm{O}$ ) by the electro-Fenton process.

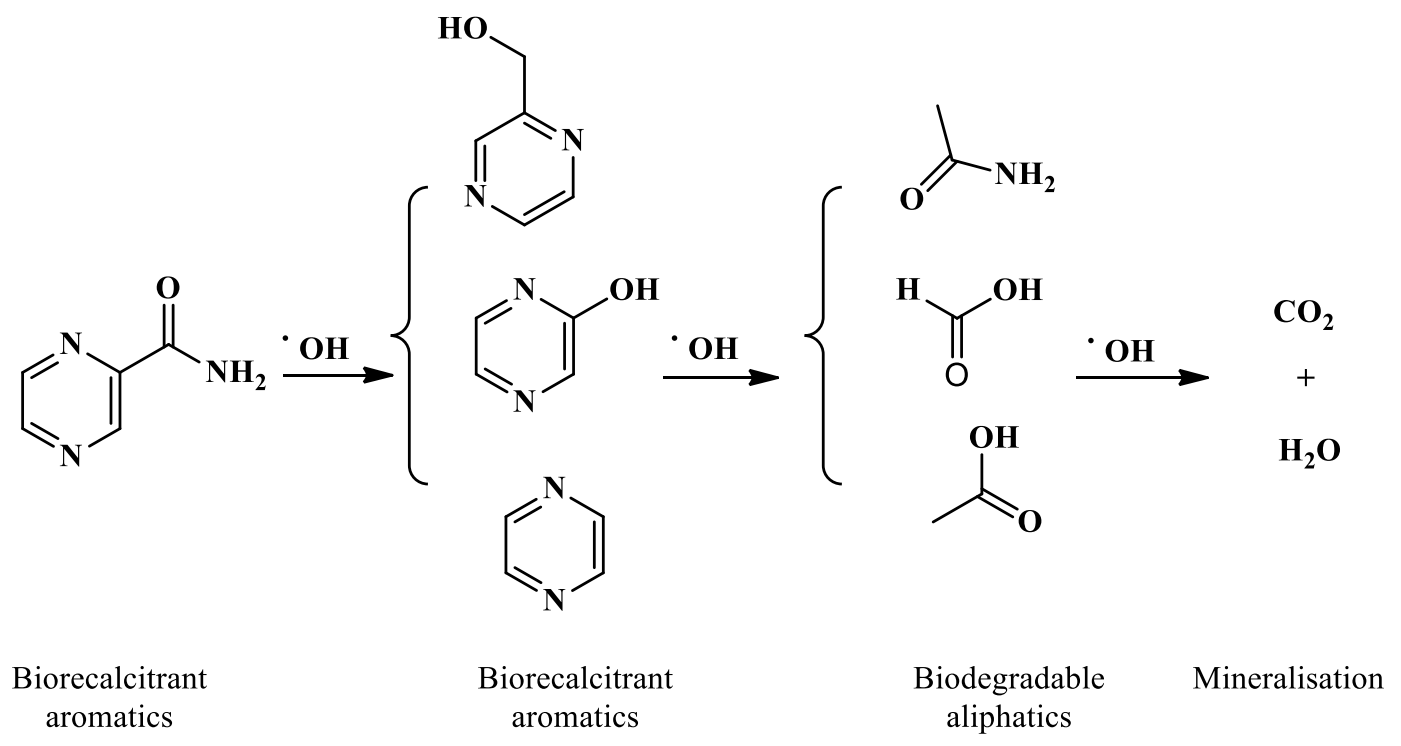

Figure 8. Global diagram of degradation/mineralization of pyrazinamide in an aqueous medium using the EF process as treatment under optimal conditions $\left(300 \mathrm{~mA}\right.$ and $\left.\left[\mathrm{Fe}^{2+}\right]=0.5 \mathrm{mM}\right)$

\section{Conclusion}

It has been found that for a $0.34 \mathrm{mM}$ pyrazinamide concentration, the optimal parameters are $\mathrm{I}=300 \mathrm{~mA}$ and $\left[\mathrm{Fe}^{2+}\right]=0.5 \mathrm{mM}$. Under these experimental conditions, pyrazinamide degrades completely after 20 min of EF treatment, and the COD 
reduction rate reaches $97 \%$ after 7 hours indicating the total mineralization of the solution.

The stable reaction intermediates identified by HPLC and LC/MS-MS are of two types: cyclic aromatic products and short-chain aliphatic products. Aromatic products are the dominant species of the solution during the first 2 hours of EF treatment. They gradually degrade afterwards to give rise to the formation of aliphatic products, which are finally mineralized with $\mathrm{CO}_{2}+\mathrm{H}_{2} \mathrm{O}$.

The biodegradability study showed that during the first 2 hours of EF treatment, the value of the $\mathrm{BOD}_{5} / \mathrm{COD}$ ratio is almost equal to zero indicating that the treated solution is non-biodegradable, thus showing that pyrazinamide and its sub - Aromatic products are bio-refractory and do not lend themselves to biological treatment. The $\mathrm{BOD}_{5} / \mathrm{COD}$ ratio reaches a value of 2.4 after 3 hours of treatment indicating that the solution, which contains mainly the short-chain aliphatic products, becomes biodegradable. These results show that electro-Fenton pretreatments can improve biodegradability by forming more biodegradable intermediates that could be easily degraded by a biological process.

Thus, a combination between electro-Fenton with a biological post-treatment could be considered as a perspective for predicting suitable electrolysis time in order to achieve good biodegradability and to pass to the biological treatment in order to minimize the cost of the global treatment.

\section{References}

1- L. Ge, C. Halsall, C. Chen, P. Zhang, Q. Dong, Z. Yao, Exploring the aquatic photodegradation of two ionisable fluoroquinolone antibiotics Gatifloxacin and balofloxacin: Degradation kinetics, photoproducts and risk to the aquatic environment, Sci. Total Environ., 633, 2018, 1192-1197.

2- G. Kaichouh, N. Oturan, M. A. Oturan, K. El Kacemi, A. El Hourch, Degradation of the Herbicide Imazapyr by Fenton Reactions, Environ. Chem. Lett. 2, 2004, 1 31-33.

3- M. A. Oturan, N. Oturan, M. C. Edelahi, F. I. Podvorica, K. El Kacem, Oxidative Degradation of Herbicide Diuron in Aqueous Medium by Fenton's Reaction Based Advanced Oxidation Processes. Chem. Eng. J., 2011, 171, 127-135.

4- U. Von Gunten, Ozonation of Drinking Water: Part I, Oxidation Kinetics and Product Formation. Water Res., 2003, 37, 1443-1467.

5- S. Bouafia-Chergui, N. Oturan, H. Khalaf, M. A. Oturan, Parametric Study on the Effect of the Ratios $\left[\mathrm{H}_{2} \mathrm{O}_{2}\right] /\left[\mathrm{Fe}^{3+}\right] /$ and $\left[\mathrm{H}_{2} \mathrm{O}_{2}\right] /$ [Substrate] on the Photo-Fenton Degradation of Cationic Azo Dye Basic Blue 41. J. Environ. Sci. Health. Part A, 2010, 45, 622-629.

6- M. A. Oturan, M. C. Edelahi, N. Oturan, K. El Kacemi, J. Aaron, Kinetics of Oxidative Degradation/Mineralization Pathways of the
Phenylurea Herbicides Diuron, Monuron and Fenuron in Water During Application of the Electro-Fenton Process. Appl. Catal., B, Environmental, 2010, 97, 82-89.

7- G. Shankaraiah, P. Saritha, D. Bhagawan, V. Himabindu, S. Vidyavathi, Photochemical oxidation of antibiotic gemifloxacin in aqueous solutions e A comparative study, S. Afr. J. Chem. Eng. 2017, 24, 8-16.

8- F. Vargas, C. Rivas, Y. Diaz, A. Fuentes, Photodegradation Pathways and the in Vitro Phototoxicity of Pyrazinamide, a Phototoxic Antitubercular Drug. J. Photochem. Photobiol., B: Biology, 2003, 87-94.

9- A. Fujishima, X. Zhang, D. A. Tryk, Photocatalysis and Related Surface Phenomena. Surf. Science Rep, 2008, 63, 515-582.

10- A. Y. C. Tong, B. Braund, D. S. Warren, B. M. Peake, $\mathrm{TiO}_{2}$-assisted Photodegradation of Pharmaceuticals, a review. Cent. Eur. J. Chem., 2012, 10, 989-1027.

11-E. Brillas, B. Boye, I. Sirès, J. A. Garrido, R. M. Rodriguez, C. Arias, P. L. Cabot, C. Comninellis, Electrochemical Destruction of Chlorophenoxy Herbicides by Anodic oxidation and Electro-Fenton Using a Boron-Doped Diamond Electrode. Electrochemica Acta 2004, 49, 4487-4496.

12-E. Brillas, M. A. Banos, M. Skoumal, P. L. Cabot, J. A. Garrido, R. M. Rodriguez, Degradation of the Herbicide 2,4-DP by Anodic Oxidation, Electro-Fenton and Photoelectron- Fenton Using Platinium and Boron-doped Diamond Anodes. Chemosphere, 2007, 68, 199-209.

13-M. C. Edalahi, N. Oturan, M. A. Oturan, Y. Padellec, A. Bermond, K. EL Kacemi, Degradation of Diuron by the Electro-Fenton Process. Environ. Chem. Lett., 2008, 1, $233-236$.

14-M. A. Oturan, N. Oturan, C. Lahitte, S. Trévin, Production of Hydroxyl Radicals by

Electrochemically Assisted Fenton Reagent. Application to the Mineralization of an Organic Pollutant, Pentachlorophenol. J. Electroanal. Chem., 2001, 507, 96-102.

15-S. Malato, J. Blanco, A. Vidal, C. Richter, Photocatalysis with solar energy at a pilot-plant scale. An overview. Appl. Catal., 2002, 37, $1-15$.

16-M. A. Oturan, I. Sirès, N. Oturan, S. Pérocheau, J. L. Laborde, Sonoelectro Fenton Process: A Novel Hybrid Technique for the Destruction of Organic Pollutants in Water. J. Electroanal. Chem., 2008, 624, 329-332.

17-E. Guevara-Almaraz, L. Hinojosa-Reyes,

A. Caballero-Quintero, E. Ruiz-Ruiz, A. Hernandez-Ramirez, J. L. Guzman-Mar, Potential of Multisyringe Chromatography for the On-line Monitoring of the Photocatalytic Degradation of Antituberculosis Drugs in 
Aqueous Solution. Chemosphere, 2015, 121, 6875.

18-G. Sathyavani, M. Sathish, A. Jerad Suresh, Forced Degradation Study of Pyrazinamide in Bulk and Formulation by UHPLC Method, American Journal of Pharmtech Research 2016 $6(3)$.

19-K. K. Koshe, U. Maniyar, M. Katariya, S. Jaiswal, V. R., G. S. Katariya, Karva. World Journal of Pharmaceutical and Life Sciences 2017, Vol. 3, Issue 1, 245-252.

20-M. A. Oturan, An Ecologically Effective Water Treatment Technique Using Electrochemically Generated Hydroxyl Radicals for in Situ Destruction of Organic Pollutants. Application to Herbicide 2,4-D. Appl Electrochem, 2000, 30, 477-482.

21-M. Sh. Yahya, N. Oturan, K. El Kacemi, M. El Karbane, C. T. Aravindakumar, M. A. Oturan, Oxidative Degradation Study on Antimicrobial Agent Ciprofloxacin by ElectroFenton Process: Kinetics and Oxidation Products. Chemosphere, 2014, 117, 447-454.

22-M. Sh. Yahya, M. El Karbane, N. Oturan, K. El Kacemi, M. A. Oturan, Mineralization of the Antibiotic Levofloxacin in Aqueous Medium by Electro- Fenton Process: Kinetics and Intermediate Products Analysis. Environ Technol, 2016, vol. 37, NO. 10, 1276-1287.

23-M. Sh. Yahya, N. Beqqal, A. Guessous, M. R. Arhoutane, K. El Kacemi, Degradation and Mineralization of Moxifloxacin Antibiotic in Aqueous Medium by Electro-Fenton Process: Kinetic Assessment and Oxidation Products. Cogent Chemistry, 2017, 3, 1290021.

24-A. Wang, J. H. Qu, J. Ru, Mineralization of an Azo Dye Acid Red 14 by Electro-Fenton`s Reagent Using an Activated Carbon Fiber Cathode. Dyes Pigments, 2005, 6, 227-233.

25-I. Sirés, N. Oturan, M. A. Oturan, R. M. Rodríguez, J. A. Garrido, E. Brillas, ElectroFenton Degradation of Antimicrobials Triclosan and Triclocarban. Electrochim. Acta, 2007, 52, 5493 - 5503.

26-E. Isarain-Chávez, C. Arias, P. L. Cabot, F. Centellas, R. M. Rodríguez, J. A. Garrido, E. Brillas, Mineralization of the Drug B-blocker Atenolol by Electro-Fenton and PhotoelectroFenton Using an Air- diffusion Cathode for $\mathrm{H}_{2} \mathrm{O}_{2}$ Electrogeneration Combined with a Carbon-felt Cathode for $\mathrm{Fe} 2+$ Regeneration. Application Catalytic B-Environnement, 2010, 96, 361-369.

27-C. M. Rui, A. F. Rossi, R. M. Quinta-Ferreira, Fenton's Oxidation Process for Phenolic Wastewater Remediation and Biodegradability Enhancement, J. Hazard. Mater., 2010, 180, 716-721.

28-S. Sonia, A. M. Polo, M. Tobajas, J. J Rodriguez., A. F. Mohedano, Degradation of Chlorophenoxy Herbicides by Coupled Fenton and Biological Oxidation. Chemosphere, 2013, 93, 115-122.

29-L. Li-An, M. Ying-Shih, M. Kumar, L. Jih-Gaw, Photo-Fenton Pretreatment of Carbofuran Analyses via Experimental Design, Detoxification and Biodegradability Enhancement. Sep. Purif. Technol., 2011, 81, 325-331.

30-M. Dorsaf, F. Fourcade, I. Soutrel, D. Hauchard, N. Bellakhal, A. Amrane, Relevance of a Combined Process Coupling Electro-Fenton and Biological Treatment for the Remediation of Sulfamethazine Solution Application to an Industrial Pharmaceutical Effluent. C. R. Chimie, 2015, 18, 39-44.

31-O. Hugo, T. Cocerva, N. Oturan, D. Buisson, M. A. Oturan, A Sustainable Integrated Process for Removal of Organic Pollutants from Water: Application to Mineralization of Metoprolol. J. Hazard. Mater., 2016, 319, 13-23.

32-A. Cyrine, F. Fourcade, I. Soutrel, F. Geneste, D. Floner, N. Bellakhal, A. Amrane, Degradation of Enoxacin Antibiotic by the Electro-Fenton Process: Optimization, Biodegradability Improvement and Degradation Mechanism. J. Environ. Manage., 2016, 165, 96-105.

33-D. Mantzavinos, E. Psillakis, Enhancement of biodegradability of industrial wastewaters by chemical oxidation pre-treatment. J. Chemistry. Technology. Biotechnology 2004, 79, 431- 454.

34-J. J. Pignatello, Y. Sun., Complete Oxidation of Metolachlor and Methyl Parathion in Water by the Photoassisted Fenton Reaction. Water Res., 1995, 29, 837-1844.

35-B. Boye, M. M. Dieng, E. Brillas, Degradation of Herbicide 4-Chlorophenoxyacetic Acid by Advanced Electrochemical Oxidation Methods. Environ. Sci. Technol., 2002, 36, 3030-3035.

36-N. Oturan, M. Panizza, M. A. Oturan, Cold Incineration of Chlorophenols in Aqueous Solution by Electro- Fenton Process. Effect of Number and Position of Chlorine Atoms on the Degradation Kinetics. J. Phys. Chem., 2009, A 113, 10988-10993.

37-H. Zazou, N. Oturan, H. Zhang, M. Hamdani, M. A. Oturan, Comparative study of electrochemical oxidation of herbicide 2,4,5-T: Kinetics, parametric optimization and mineralization pathway. Sustainable Environ. Res., 2017, 27, 15-23.

38-H. Olvera-Vargas, T. Cocerva, N. Oturan, D. Buissonb, M. A. Oturan, Bio electro-Fenton: A sustainable integrated process for removal of organic pollutants from water: Application to mineralization of metoprolol, J Hazard Mater, 2016, 319, 13-23. 